\title{
Contribution to the knowledge of the Placentation of the Cape Goldmole (Chrysochloris)
}

\author{
BY
}

\author{
Dr. DAN. DE LANGE JR.
}

(With plate IV-VII).

Setting in order the literary inheritance of late prof. A. A. W. Hubrecht I found some interesting notes upon two series of sections through young uterine swellings of Chrysochloris probably made bij Mr. Arthur Willey of Montreal. These notes directed my attention to the placentation of this insectivore. Therefore as prof. Max Weber asked my, collaboration to the memorial number of "Bijdragen tot de Dierkunde" for Dr. Kerbert's seventieth anniversary, I resolved, after cutting some more series of slightly older stage, to investigate this subject in order to come to some provisional conclusions.

The Embryological Institute at Utrecht disposes of some ten uteri of Chrysochloris, five or six of which are pregnant, while the remaining are in virginal or puerperal conditions. The diameter of the swellings ranges from 5 to $18 \mathrm{mM}$. Chrysochloris possesses a pronounced uterus duplex and in all pregnant objects there is a uterine-swelling on both sides.

I. Youngest stage of the collection $\left(\mathrm{N}^{\circ} .2 \alpha\right.$ of the catalogue), diameter $5 \mathrm{mM}$.

The series is cut transversal to the main direction of the uterus and begins at the vaginal side of the swelling. Fig. $1 a$ represents one of the first sections of the gestationsack drawn in a low power. The mesometrical side of the uterine mucosa is strongly swollen and shows numerous uterine glands (u. g.) and rather numerous bloodvessels (b.v.) of small diameter with distinct endothelium (vide Fig. $1 b$ i. e. a part of Fig. $1 a$ drawn under a high power). In this mucosal thickening a deep groove is present pointing to the root of the mesometrium (mes. gr.) and dividing the thickening into two not exactly equal parts. The anti-mesometrical portion of the uterine mucosa is thin, possesses a few glands and is almost devoid of bloodvessels. The uterine epithelium-cells are throughout highly cylindrical. The swollen condition of the mucosa at the mesometrical side is the normal one, the mucosa of virginal or regenerate uteri presenting a very thick layer with rather numerous glands, the cavum uteri being relatively small but showing very deep grooves. The thinning of the mucosal layer at the opposite side is caused by pregnancy. The reader will observe the important thickness of the muscularis mucosae of which only the inner layer of circular muscle-fibers is drawn (compare fig. $1 a$, with figg. $2,3,5$ and 6 ).

As the wall of the germbladder appears these cushions of the uterine mucosa diminish in height, at first on the left side afterwards on the right side, while on the whole circumference the uterine mucosa becomes thinner. The result is that the mucosal wall of 
the maternal gestationsack consists of a very thin antimesometrical part with a few flattened glands, of a somewhat thicker mesometrical part with better developed glands and of two lateral thickened pads with numerous uterine glands and peculiar syncytial modifcations of the uterine bloodvessels which play an important part in forming the placental bloodlacunes. The uterine epithelium has become cubical instead of cylindrical. At the mesometrical side the germbladder shows from the beginning more or less clearly the formative epiblast of the blastodisk. The embryonic area therefore is situated at the vaginal and mesometrical side of the swelling. It is cut in an oblique sagittal direction and since the embryonic region shows moreover a very marked lateral flexure the right localization of its different parts is not very easy. Evidently there is no amnion or allantois and the medullary groove is not yet closed, while a large primitive streak is present. At the embryonic side the wall of the germbladder consists of a thick layer of formative epiblast with cilindrical cells, of a rather thick layer of somatic mesoblast with polygonal cells without coeloma or somites and of a thin layer of hypoblast with flat cells. At the opposite side the wall is formed of epiblast (i. c. trophoblast) and hypoblast (yolk-) only, since the mesoblast is wan ting in this stage in the antembryonic half of the germbladder. Behind the primitive streak an extensive ventral mesoblastlayer is present. In more central sections a voluminous exocoeloma appears within this ventral mesoblast. Two anterior horns of the exocoeloma extend on either side of the primitive streak. Notwithstanding the presence of an exocoeloma the greater part of the germbladder in young stages is filled up by the umbilical vesicle. Chrysochloris may therefore be ranged with the animals of the macromphaloild egg-type (vide figg. 2, 3 and 5). At the antembryonic pole the wall of yolksack shows numerous bloodspaces filled with haematoblasts without there being question of rudiments of heart or -vessels within the formative mesoblast. Thus the area vasculosa extends on the whole surface of the umbilical vesicle. In no stage a sinus terminalis can be observed.

Fig. 2 presents a somewhat diagrammatical section of this region of the germbladder drawn in a low power. The mesometrium isturned upwards as is the embryonic shield. In the latter we can distinguish from the right to the left: the thickened cerebral plate (cer. pl.) with the. important anterior cerebral groove. At this spot epiblast and hypoblast are touching each other, thus separating the prochordal (cephalic) mesoblast of hypoblastic origin from the chordal (somatic) mesoblast rising from the dorsal plate (and perhaps partly from the protochordal plate) thus being mainly of epiblastic origin.

A thickened band of formative epiblast, the lateral part of the medullary plate connects the cerebral plate with the primitive streak where epiblast and mesoblast pass continuously into each other, while the hypoblast is loosely attached to it. Behind the primitive streak stretches the ventral mesoblast separated both from epi- and hypoblast. At its distal end a small cavity is seen, the beginning of the exocoeloma. The antembryonic half of the germbladder is devoid of mesoblastic elements, the wall consisting of a thin layer of trophoblastand yolk-hypoblastcells. Sometimes both membranes lay close together, sometimes they are separated by, large bloodlacunes filled with numerous haematoblasts but without endothelium. The umbilical vesicle is seen filling almost the whole space of the germbladder.

In this region there is no connection whatever between trophoblast and uterine mucosa. The latter shows two distinct thickened pads one on the foreside of the embryonic area (the right side of the drawing), one on the hind side of the embryonic area, facing the ventral mesoblast and the exocoeloma (the left side of the drawing). The first mentioned thickening of the uterine mucosa possesses numerous uterine glands and a few syncytial clusters and shows some ostia of the glands in the cavum uteri. At this side of the uterine wall the trophoblast of the germbladder will never become coherent with the uterine mucosa. We may call it the false placental pad. In the left hand thickening the number of the glands is much smaller, while syncytial clusters and small bloodspaces are crowded at its surface. We also remark numerous bloodvessels and bloodlacunes at this spot in the muscular sheet of the uterine wall. We may call this mucosal thickening the true placental pad 
or the pläcental pad s. s. since trophoblast and uterine mucosa will grow together at this spot in more central sections to form the placental cushion.

i. In central direction the exocoeloma rapidly increases in extent. The coelomic space of fig. 2. appears to be the right horn of the exocoeloma. Some 70 sectiones centrad we find another coelomic space before the primitive streak. In reality this ought to be to the left of it, the oblique cutting-direction causing this optic deceit. As the primitive streak disappears some 15 sections centrad, the two horns unite to a large common space, which covers about a third of the circumference of the germbladder at its hind side.

In the meantime the embryonic area has disappeared, some traces of the somatic mesoblast still are visible, while the number and extent of syncytial clusters in the true placental pad have increased, the few uterine glands having hypertrophied (especially at their mouth in the uterine cavity). The exocoelomic part of the germbladder lies just opposite to the placental pad and these two structures are approaching each other, as the germbladder grows larger.

Fig. 3 presents a section through this region of the gestationsack. We observe the large germbladder nearly filling the cavum uteri. The true placental pad at the left side is obviously thicker and shows much larger syncytial clusters than the false one on the right side.

The exocoeloma covers the hind part of the germbladder, at the ventral side rudiments of the area vasculosa are seen. The greater part of the anterior wall of the germbladder is formed by hypoblast and trophoblast only, laying close together. At the dorsal side we may observe some traces of the somatic and of the ventral mesoblast.

By the time that the trophoblast membrane which covers: the exocoeloma, nearly touches the now very flat uterine epithelium, there appears within the exocoelomic space an island of cells. This soon grows together with the outer wall of the exocoeloma. These cells form part of the placental cushion. The latter has the form of a toadstool the margin of which projects into the exocoeloma of the germbladder. About six sections centrad placental pad and placental cushion grow together and the separating layers of the trophoblast and the uterine epithelium disappear.

Fig. 4 gives us a scheme of a marginal section through the placental cushion when it has already united with the placental pad. On the upperside it is bordered by the thin mesoblastlayer of the exocoeloma. From the periphery inwards follow a.layer of cylindrical eytotrophoblastcells and the syncytial layer of the plasmoditrophoblast. The latter shows many outgrowths in the subjacent maternal trophospongia which are engaged in surrounding the maternal bloodspaces with a syncytial pseudendothelium. The plasmoditrophoblast gradually passes into the very loose connective tissue of the maternal trophospongia. (Willey calls it dermatic proliferation, but I can't see the necessity of the introduction of new names). This tissue shows numerous empty spaces which could be presented only partly in the drawing in consequence of their smallness. They do not show bloodcoagulations as do the above mentioned peripheral ones. Since both systems of lacunes are evidently in connection with each other, I don't think this fact is of principal importance. The accumulation of bloodplasma in the periphery of the placental cushion will probably be caused by the contraction of the tissues. when fixed. The blood will have been pushed under these circumstances to the spots of least resistance.

Syncytial clusters do not contribute to the structure of the placental cushion proper, but remain limited to the placental pad underneath the latter. They also show several gaps and spaces with or without bloodcoagulum which communicate with the ones in the trophospongia of the placental cushion. The greater part of the uterine glands have disappeared in the placental region. In fig. 4 we remark one normal gland on the left side and in the middle of the drawing a hypertrophied one with degenerated, flat epithelium filled with bloodcoagulum. The last mentioned structure however might present the combination of a trophospongial space with a hypertrophied bloodcapillary.

The connective tissue of the placental pad is much denser than that of the placental 
cushion and shows concentrated masses of nuclei, though it possesses also empty spaces of greater or less extent. We might call these structures trophospongial clusters. It is now perhaps suitable to enter into some details upon the origin and development of the syncytial clusters. If we investigate the false placental pad with a high power system, we may detect that in central direction the bloodcapillaries increase in extent. The endothelial wall hypertrophies, thus the bloodspaces are gradually filled up with syncytial masses which show big, sometimes even giant nuclei (vide figg. 10 and 11). Since the bloodcoagulum impregnates the whole syncytial mass, the latter is darkly stained. In the figures 2, 3, 8-11, these dark masses are presented in the drawing by a black tone as are the bloodfilled spaces, in the remaining figures the syncytial clusters are characterized by double hatching. In the figures 8, 10 and 11 we may observe small syncytia of the non-placental side next to genuine bloodcapillaries and transitional stages where the bloodspace is not yet wholly filled up by the hypertrophying endothelium. Fig. 9 is a detail from the placental side of the same region drawn in the same power as fig. 8. One easily can detect the difference in size between the large syncytial masses of this side and the much smaller ones of the false placental thickening. I also draw the attention to the widened mouth and the irregular outline of the epithelium of the uterine gland in the middle of this drawing.

In the non-placental pad the distribution of the syncytial clusters is rather regular, the denseness of it and the size of the individual clusters increasing slightly from the periphery to the centre. In the true placental pad on the other hand the syncytial masses are heaped together round the outer margin of the placental cushion encircling the plane where the latter is fixed on the placental pad, though they are tolerably numerous in the part of the placental region below this plane (vide figg. 4, 5 and 7 ). In this region they are mixed up with the above mentioned trophospongial clusters. We easily may detect clods of these cells surrounded by syncytials masses. As the clods also may show gaps and. fissures partly filled with blood, it is sometimes very difficult to distinguish these masses from the true vasogene syncytia.

Finally the few uterine glands of the centre of the placental pad show signs of degeneration. The epithelium at first cilindrical becomes cubical or flat. The chromatine of the nuclei clumps together, while the total size of the glands increases and the hypertrophied space in some cases is partly filled with bloodcoagulum (vide Fig. 6). Though I have not been able to observe all the connecting transitional stages, I have received the impression that the widened spaces of some uterine glands may contribute to the extension of the trophospongial bloodspaces into the basal layer of the placental pad, after the gland cells have been destroyed by maternal leucocytes, which are scattered through the maternel tissue in the proximity of the bloodspaces.

The bloodlacunes of the ripe placenta may therefore be of triple or quadruple origin:

$1^{\circ}$. By widening of the original interfibrillar spaces of the connective tissue of the uterine mucosa.

$2^{\circ}$. By degeneration and ruin of vasogene, syncytial masses.

$3^{\circ}$. By degeneration and ruin of trophospongial clusters i. e. of concentrated masses of tro. phospongial cells in the placental pad.

$4^{\circ}$. By degeneration and ruin of uterine glands.

In more central sections the foetal trophoderma penetrates deeply into the maternal trophospongia especially in the middle of the section where a deep pit is seen at the surface of the placental cushion and the bloodlacunes largely increase in size (compare fig. 4 with figg. 5, 6 and 7). Bodily reconstructed the trophoderma has the form of a inverse cone its base bordering the exocoeloma and its top penetrating into the placental cushion. This cone shows many irregular outgrows which tit into sinuosities of the hollow trophospongial disk. In the centre the trophoderma reaches to the basal part of the placental pad. In this region 
the placental cushion is formed almost of foetal elements only. Figg. 5 and 6 may illustrate this. In the first-mentioned figure the whole gestationsack is presented. It is drawn in a low power and gives a schematic idea of the main facts. The wall of the germbladder consists for the greater part of trophoblast and hypoblast only, the formative epiblast and the somatic mesoblast having disappeared. At the upper side some traces of the ventral mesoblast are still visible and the hind side (left side of the drawing) of the umbilical vesicle is covered with the longitudinally stretched, narrow exocoeloma. The placental cushion is seen feebly projecting into this space. It consists mainly of enormous bloodlacunes surrounded by trophodermic tissue (hatched in the, drawing). Laterally some trophospongial elements contribute to the structure. The trophodermal cone enters in the centre into the subjacent part of the placental pad. The latter consists of lacunar connective tissue with some syncytial clusters and a few degenerated and hypertrophied uterine glands. The false placental pad on the right side of the drawing shows the same features as in the previously treated sections.

In fig. 6 some more pecularities may be detected inconsequence of the use of a higher power of magnifying. We observe the finely dotted plasmoditrophoblast surrounding the bloodspaces as a narrow sheet. In some places it is cut tangentially and then it forms broad bands as on the right side of the placental cushion. The coarsely dotted cytotrophoblast has no connection with the bloodspaces or with the trophospongia, it is everywhere covered on its basal side by the syncytial layer of the plasmoditrophoblast. The large double hatched serpentine on the right side of the trophodermal cone is a region where the maternal tissue is degenerating and bloodlacunes are about to be formed. By want of means of distinction it is presented in the same manner as are the syncytial masses, which are seen mixed up with the trophospongia] clusters. To the left of the trophodermal cone a long stretched, hypertrophied uterine gland is, present. To the right of it a gland is seen partly filled with blood. Finally we may remark that the syncytial masses and extravasates also extend into the layer of circular muscles.

As the sections have passed the middle of the placenta the exocoelomic space gradually contracts, retiring in ventro-dorsal direction. The result is that the placental cushion becomes connected with the hypoblast of the umbilical vesicle and that the mesoblastic covering disappears in ventro-dorsal direction (from right to left in the drawing). At last the whole surface of the cushion is covered by yolkhypoblast. However it is nowhere in contact with the bloodlacunes of the area vasculosa, the hypoblastic covering of this region being devoid of bloodspaces.

Fig. 7 gives a section through this region of the placenta. The exocoeloma has not yet disappeared totally, but still covers the dorsal (left) side of the placental cushion, the other half being bordered by the umbilical vesicle. The trophoderma has still a conical form and possesses large bloodspaces. In the central part of the placental pad we may distinguish large trophospongial clusters, empty spaces, blood lacunes and a few glands. The syncytial clusters are especially crowded round the margin of the cushion. Mind the large blood spaces and bloodvessels in the muscularis uteri.

At its proximal end the series shows in the main points the same pecularities as I have previously described. at the distal one. As the exocoeloma has retired from the placental eushion, the syncytial masses of the false placental pad disappear and this side of the uterine mucosa shows an increasing number of glands and obviously becomes thicker, while a deep groove appears within this glandular cushion, laying at a distance of $\pm 135^{\circ}$ from the point of attachment of the mesometrium.

A few sections behind the disappearance of the mesoblast and the exocoeloma, the wall of the germbladder consisting throughout of trophoblast and hypoblast only, the placental cushion separates from the placental pad and soon disappears. The latter still shows enormous syncytial masses and widened uterine glands begin to reappear in it. In the meantime the above mentioned antimesometral grove has become very deep and the mucosa pierces at 
this spot the muscular wall of the uterus. Finally the groove separates from the cavum uteri, it presents the beginning of the tuba. The right side of the sections therefore agrees with the medial side of the uterus and the placenta lies at the lateral one. Some twenty sections further on the syncytia of the true placental pad disappear, the uterine mucosa acquires a more or less regular ranged, glandular character. After a few sections we also can detect no more traces of the germbladder.

$$
\text { - }
$$

II. $\mathrm{N}^{\circ}$. $-1 a$ of the catalogue, diameter of the uterine swelling $6 \mathrm{mM}$.

Though the size of the uterine swelling $\mathrm{N}^{\circ} .1 a$ is only slightly larger than that of $\mathrm{N}^{\circ} .2 a$, the development of germbladder and placenta evidently shows a further stage. Especially in the embryonic area the difference between these two stages is great. In $\mathrm{N}^{\circ}$. $1 a$ the neural tube and the amnion-cavity are wholly closed and the encephalon already shows a differentiation in the three primordial vesicles. Optic vesicles are present. The cephalic flexion is obvious and in consequence the head-region projects into the yolksack being covered by a narrow proamnion (v. fig. 14). Pericard and heartrudiment are highly developed and we may observe the principal vessels of the arterial and venous systems (aorta, carotis, venae omphalomesentericae, etc.). The foregut has differentiated from the hypoblast which for the rest is spread out flatly and is throughout continuous with the yolksackwall, except in the region of the allantoic bladder, the latter having separated from the umbilical vesicle, communicating with it through a narrow opening. The allantois projects into the exocoeloma without participating in the structure of the placenta.

The area vasculosa shows everywhere numerous bloodvessels with an endothelial wall. As we can observe in fig. 14 the orientation of the embryonic region has greatly changed. The embryo lies no more at the mesometrical side of the uterus, its longitudinal axis being more or less perpendical to the mesometrical plane, but it has shifted to the centre of the germbladder and its main axis has acquired a direction parallel to the mesometrium. On the ventral side (the right one in the drawing) it is covered by the umbilical vesicle, on the dorsal side by the enlarged exocoeloma which occupies nearly half of the germbladder. Thus the back of the embryo nearly touches the placental region, being separated from the latter by the thin amnion only. The mesoblastic covering of the exocoeloma shows no traces of bloodvessels with exception of the spots where it borders the area vasculosa and thus the placenta still is devoid of foetal bloodvessels, since the partly hypoblastic covering of the foregoing stage is wholly pushed away by the mesoblastic one.

In the embryonic region the differentiation of the mesoblast has rapidly progressed. A spacious embryonic coeloma and a large pericardial cavity have arisen, the former being in wide communication with the exocoeloma at the hind part of the embryonic area and \pm 18 somites have been formed.

Concerning the structure of the placental cushion and of the two placental pads principal changes have not occurred in it. Especially the false placental pad shows the same features as in the foregoing series. The syncytial clusters however show signs of reduction. The placental cushion has increased in size and projects much further into the exocoeloma. The bloodspaces are much more numerous, the increase being especially evident in the marginal region. Here the maternal trophospongia has been largely reduced. Probably the greater part of the cells have been destroyed and are replaced by trophodermal elements (plasmoditrophoblast). At any rate one can't distinguish with certainty trophospongial elements contributing to the formation of the placental cushion proper and one obtains the impression that it consists of a cortex of cytotrophoblast with radiating branching ingrowths and of bloodspaces with a thin coating of plasmoditrophoblast (compare for the difference between $\mathrm{N}^{\circ}$. $2 a$ and $1 a$ fig. 14 and 15 with fig. $4-6$ ).

Remarkable are the shallowness of the central pit and the low development of the other sinuosities of the surface of the placental cushion. In the preceding stage $N^{\circ} .2 a$ and in the following ones $\mathrm{N}^{\circ} .9$ and 10 these hollow invaginations are much larger and will play 
an important part in preparing the foetal vascularisation of the placenta (compare fig. 12 and 13, with fig. 5, 6, and 18-23). The structure of the subjacent placental pad has some how been simplified. The uterine glands have been destroyed and the remains have nearly disappeared. The empty spaces of the syncytial and trophospongial clusters have augmented in number and extent and can't be distinguished from each other. For this reason the placental pad shows a more spongious and simple structure than in $\mathrm{N}^{\circ}$. $2 a$.

The above-mentioned spaces are in connection with the bloodlacunes of the placental cushion especially at the margin of the plane of attachment. On the basal side they penerate within the layer of circular muscles and acquire connection with the venous system of the muscular wall of the uterus. The fig. 12 and 13 are details drawn under high power which illustrate the transition of a vein of this region into the lacunar system of the clusters. In the proximity of the bloodlacunes we may. observe numerous leucocytes.

The arterial system on the other hand has a direct connection with the bloodspaces of the trophoderma without intermediate of the lacunes of the clusters. In the fig. 16 and 17 the reader may observe a central artery which is travelling towards the surface of the placental cushion. In the first mentioned figure it is on the point of branching. In the last one it has already divided. One branch remains in the basal layer of the placental pad while the other unites with a large bloodspace in the trophoderma. In the following sections its muscular wall gradually disappears. The basal branch is also visible in fig. 15 and this branch enters in communication with the arterial system of the muscularis uteri.

Even in this relatively advanced stage there is no direct contact between the maternal and foetal capillary-system, the latter remaining limited to the area vasculosa of the yolksack which nowhere has any connection with the placental region. In the centre of this region, after the disappearance of the embryonic area, the area vasculosa borders the inner wall of the exocoeloma and thus lies close to the placental cushion only separated from it by the narrow exocoelomic space (v. fig. 15). The oxygen and the anabolic materials of the maternal system therefore are obliged to penetrate into the exocoelomic fluid by osmotic interchange and in the same manner these substances will progress from this fluid into the blood circulation of the area vasculosa or into the yolksack before reaching the embryonic region. The catabolic material of this region will progress in inverse direction. After attaining the trophodermal bloodspaces it will be transported at the margin of the placental cushion into the underlying trophospongial lacunar system and finally be removed into the maternal venous system of the muscularis uteri.

III. $\mathrm{N}^{\circ} .9$ of the catalogue, diameter of the uterine swelling $7 \mathrm{mM}$.

Though the gestationsack of $\mathrm{N}^{\circ} .9$ is obviously larger than the one of $\mathrm{N}^{\circ} .1 a$ and the placenta presents a further developmental stage, the embryonic region has lagged behind. A neuroporus is present and the mednllary tube has for the greater part not yet closed. The differentiation of the braintube has only just begun. The cephalic flexure is not very obvious and in consequence the proamnion is still rudimental (v. fig. 18). At the hindside the lateral amnion folds have united with the tailfold (v. fig. 20), but in the anterior trunk. region and in the greater part of the beadregion no amnionfolds can be detected. A pericard and a straight hearttube are present, but the differentiation of this region is much lower than in $\mathrm{N}^{\circ}$. Ia. I have not observed any bloodvessels with undeniable endothelial walls in the embryonic area, but perhaps venae omphalomesentericae are present and one obtains the impression that the vessels of the area vasculosa possess a real wall of their own. The outer wall of the exocoeloma is still devoid of bloodvessels.

Fig. 18 gives a schematic idea of the relative position of the embryonic region, the placenta, the mesometrium etc. 'The sections are cut in an obliquely transverse direction to the main axis of the embryo i. e. from left-anterior to right-posterior. The embryo shows the same position as the one of $\mathrm{N}^{\circ}$. $2 a$. It is laying at the mesometrical side of the germbladder between the two placental pads, the caudal region being directed towards the true placental 
pad. If the headregion "should dive into the yolksack and the amnion cavity be closed, the position of the embryo in relation to the exocoeloma and the placental region would be just the inverse of that in the series $\mathrm{N}^{\circ}$. $1 a$, i. e. the ventral side of the embryonic region would be turned towards the placenta and the exocoeloma and the dorsal side towards the yolksack.

Concerning the embryonic region we may remark that the foregut has differentiated from the yolksack, the remaining part of the gut wall being still continuous with the coating of the umbilical vesicle. Some 8 somites are visible, but in consequence of the tranversal cutting-direction the number can't be determined exactly. Besides the pericard with the heartrudiment, paired embryonic coelomasacks are present, the right one (the left one of the sections) being in connection with the exocoeloma. At the end of the segmented region of the trunc the right (left of the sections) amnionfold appears, \pm 40 sections backwards the left one becomes visible. In the meantime the medullar tube flattens to a broad plate and grows together with the mesoblastic layer which has become solid, forming together the primitive streak and the two lateral amnionfolds unite with the tailfold. In consequence of the oblique cutting direction this junction takes place in an asymmetrical way viz. the right fold (being at the same time the caudal one) progressing much faster than the left one. As result of this process a continuous amnion now covers the primitive streak and the left lateral coelomic space unites with the exocoeloma above the amnion (vid. fig. 20).

An entodermal allantois still is wanting. Perhaps a mesoblastic thickening at the right (hind) side of the tailfold which is visible in nearly 30 sections, presents a rudiment of a mesoblastic allantoic outgrowth. Anyhow there is no question of this allantoic rudiment exercising any influence upon the formation of the placenta as we many conclude from the circonstance that series $\mathrm{N}^{\circ} .1 a$ with an evident and relatively large entoblastic allantois has a less developed placenta than series $\mathrm{N}^{\circ} .9$ which is devoid of an entoblastic allantoisrudiment.

The false placental pad of this stage is characterized by very spacious uterine glands with a thin wall and. by a reduction of the syncytial clusters. It gradually takes a more ore less puerperal appearance. In the true placental pad on the other hand nearly the whole mucosal part is syncytial and shows large, anastomosing empty spaces which communicate on the basal side with the maternal venous system and on the apical side with the bloodspaces of the trophoderma. In the placental cushion the maternel trophospongial part has almost disappeared especially in central sections. The trophodermal ingrowths have largely increased and penetrate in the centre into the underlying syncytial tissue of the placental pad. The large anastomosing trophodermal bloodlacunes are throughout surrounded by a pseudendothelium of plasmoditrophoblast which is fully. separated from the cytotrophoblastic villi by narrow empty spaces ( $\mathrm{v}$. fig 21 ). These villi are partly hollow and these small cavities will in future obtain connection with the wide and deep peripheral pits which characterize this stage of the placentation and the following in opposition to the foregoing. one (compare figg. 14 and 15 with figg. 18 and 19). The mesoblastic covering of the placenta does not coat these pits in this stage bnt forms bridges across their mouth (vide figg. 18-21). This hollowing of the cytotrophoblastic villi will prepare the ingrowth of the foetal bloodvessels of the exocoelomic mesoblast into the trophoderma a process occurring in the following stage. In series $\mathrm{N}^{\circ}$. 9 the outer wall of the exocoeloma being still devoid of foetal vessels there can be no question of this phenomenon.

The circulation of the maternal blood in the placental lacunar system of this stage takes place in the manner already previously described. Maternal arteriae of the muscularis uteri penetrate through the syncytial tissue of the placental pad towards the centre of the trophodermic cone (v. figg. 19 and 21) and enter in communication with the trophodermal bloodlacunes. On the other hand these spaces are in connection with the vacuities of the syncytial tissue in the placental pad especially at the margin of the placental cushion. In 
their basal parts these spaces penetrate into the muscularis uteri and obtain connection with the maternal venous system (v. fig. 19).

\section{IV. $\mathrm{N}^{\circ} \cdot 10$ of the catalogue, diameter of the uterine swelling $8 \mathrm{mM}$.}

This series has been damaged seriously in cutting. In consequence a part of the sections are badly. deformed, especially the embryo proper and the embryonic coverings. Happily the placenta has remained intact for the greater part, but the whole gestation sack has been stretched parallel to the mesometrical plane and has been flattened perpendicular to the latter. The cutting-direction is obliquely horizontal in relation to the main axis of the embryo and the orientation of the latter is more are less the same as in the series $\mathrm{N}^{\circ} .1 a$. It is lying in the centre of germbladder with its right upperside close to the surface of the placental cushion and its longitudinal axis is parallel to the mesometrical plane. The tail has grown out and describes a semi-circle under the ventral region of the body, the end lying on the right side of the head-region.

In consequence of this circumstance we will meet thrice with the neural canal in fig. 22, once in the head-region (mind the optic vesicle), a second time in the posterior trunc-region and a third time in the tail.

Embryo and placenta are much higher developed than in the preceding series. On account of the damaged state of the embryo I will not enter in details upon the structure of the former, but I will only mention the facts that four visceral pouches are visible, the first two possessing an outer aperture, that the auditory vesicle has differentiated into sacculus and utriculus and that a epiblastic lenticular thickening is present at the outer side of the optical vesicle. The vascular system is already highly developed and the exocoelomic mesoblast shows numerous large vessels communicating with those of the embryonic area. $\mathrm{Nu}-$ merous somites and nephridial rudiments are present.

Concerning the placentation of this stage I only will make a few remarks. The false placental pad has been reduced and is only slightly thicker than the remaining part of the uterine mucosa. The placental cushion has strongly increased in size and is nearly twice as large as in the preceding stages. Its apical covering is still formed by the outer mesoblastic layer of the exocoeloma and is filled up with smaller and larger bloodvessels which enter into the spacious pits and into the cytotrophoblastic villi of the placenta (vide figg. 22 and 23).

The cortex of the placental cushion thus consists of two intermingled reticula of bloodspaces, the foetal capillary system penetrating in centripetal direction, the maternal bloodlacunarsystem progressing in centrifugal direction, the latter being [covered by a pseudoendothelium of plasmoditrophoblast. The two systems may easily be distinguished from each other, the maternal one being filled with bloodcoagulum and showing no bloodcorpuscules with exception "of some leucocytes, the foetal one lacking bloodplasma but showing numerous nucleated haematoblasts.

Fig. 24 presents a tangential section through the margin of the placental cushion. The maternal bloodspaces are presented by a black tone and are surrounded by a plasmoditrophoblastic layer characterized in the drawing by black nuclei and by the absence of celllimits. The cytotrophoblastic covering of the foetal vessels which in opposition to the maternal bloodspaces possess a wall of their own and show numerous haematoblasts, is indicated by the dotted condition of the nuclei and by the presence of cell-limits. At the periphery we may observe the foetal vessels of the exocoelomic wall penetrating into the trophoderma of the placental cushion.

In the figg. 22 and 23 we may obtain a general idea of the structure of the centre of the placental region. We may observe the numerous large pits penetrating from the surface to the basal parts of the cushion being filled up partly by branching foetal bloodvessels. These vessels belong to the vascular system of the exocoelomic mesoblastic wall, the allantois not yet participating in the structure of the placenta. In the peripheral layer the 
maternal and foetal circulatory system are seen intermingling, centrad the trophoderma shows smaller and larger spaces partly filled with maternal blood and partly empty.

In figg. 22 a large bloodspace of the placental pad probably of arterial character is seen in the centre communicating with the peripteral bloodspaces of the trophoderma. In fig. 22 on the other hand the same phenomenon is seen more laterally. Probably this is a connection of the maternal venous system with the trophodermal one through the intermediate of the trophospongial lacunes.

$r_{\text {. }}$

The placental pad is characterized by enormous spaces surrounded by syncytial masses and these spaces are partly filled with blood, partly empty. The muscularis underneath the placental pad also. shows at several spots large accumulations of blood-coagulum and enormous empty spaces, this phenomenon being probably in connection with the large providing with blood of the placental region which is necessary to entertain the metabolism of the developing germbladder.

Finishing this description I will once more lay stress upon the circonstance that in Chrysochloris an intricate placental structure and bloodcirculation are formed without intermediate of the allantoic circulatory system, the development of placental cushion and pad depending only on the stimulus of the attachment of the germbladder to the uterine wall by the trophoblast.

\section{CONCLUSIONS.}

1. In the pregnant uterus of Chrysochloris the uterine mucosa shows at both sides of the mesometrium two placental pads. These structures have not been preformed in the virginal or nonpregnant condition, the uterine mucosa then possessing an enormous and uniform thickness.

2. The medial pad is only slightly thicker than the remaining part of the mucosal wall, shows peculiar changes of the uterine glands and of the bloodcapillaries and never comes in contact with the wall of the germbladder. Therefore I call it the false placental pad.

3. The lateral one shows a much larger diameter and grows together with the wall of the germbladder to form the discoidal placenta. Therefore it may be called the true placental pad.

4. The embryonic area of the germbladder is lying at the mesometrical side of the uterus. Its caudal region with the ventral mesoderm and the exocoeloma is turned towards the true placental pad.

5. The part of the placental pad which grows together with the trophoblast, projects into the exocoelomic cavity and has been called placental cushion.

6. The placental cushion consists for the greater part of a large conical ingrowth of the trophoblast: the trophoderma s. ectoplacenta which differentiates into a thin outer syncytial coating of plasmoditrophoblast and inner epithelial proliferations of cytotrophoblast. The former gradually forms a pseudendothelial covering round the maternal bloodspaces which originally arise in the maternal trophospongia i. e. in the connective tissue of the uterine mucosa having taken a spongious character. In the first stages the trophospongia forms a saucerlike surrounding of the inverted trophodermal cone, in older one's it is pushed away by the lateral spreading of the latter. Thus the placental cushion consists in these stages of an enormous trophodermal pad which contains numerous maternal bloodlacunes surrounded by a plasmoditrophoblastic pseudendothelium and a reticulum of cytotrophoblastic villi forming a conducting tissue for the foetal capillary system.

\%. In the subjacent placental pad proper the tissue gradually becomes syncytial and large bloodspaces arise in various modes. The bulk of them are furnished by the hypertrophying of maternal bloodcapillaries forming spongious syncytial clusters, but concentration of nuclei of the connective tissue at definite spots causing the formation of spaces 
at other spots and degenerative processes of the uterine glands which occur with the auxiliary of leucocytes spread throughout in the tissue of the placenta, may contribute to the formation of its spongious structure.

8. The circulation of the maternal blood in the placental region chiefly takes place in the following way: arterics of the muscularis uteri penetrate through the spongious tissue of the placental pad to the top of the trophodermal cone and anastomose with the trophodermic bloodlacunes. The arterial maternal blood, abundant in nutritive substances spreads from the centre to the periphery of the placental cushion and gradually looses its oxygen and nutritive elements in the first stages to the fluid of the exocoeloma, in elder stages to the blood of the foetal capillary system. Having absorbed catabolic material from the foetal liquids the maternal blood becomes venous and flows to the anastomosing spaces of the placental pad which again largely communicate with the venous system of the muscularis uteri and in this manner the catabolic products of the foetal circulation are carried away.

9. In the investigated stages the allantois and the allantoic circulation play no part whatever in the formation and function of the placenta. The latter arises under the stimulus of the attachment of the germbladder to the uterine mucosa and consists in the above mentioned stages of a foetal trophodermal ingrowth with a thin covering of exocoelomic mesoblast and of the hypertrophied and altered mucosa uteri i. e. of the maternal trophospongia. The foetal capillary system of the placenta belongs to the outer wall of the exocoeloma. Bloodvessels of the area vasculosa, or the allantois do not contribute to this system. 
EXPLANATION OF THE PLATES.

\section{LIST OF ABBREVIATIONS.}

all. allantoisrudiment

amn. anmion.

a. v. bloodvessels of the area vasculosa.

b.l. bloodlacunes.

b.v. bloodvessels.

b. t. brain tube.

c. a. central artery of the placenta.

cer. pl. cerebral plate.

c. $t$. $m$. connective tissue of the mucosa uteri.

ch. m. chordal mesoderm.

c.tr. cytotrophobast.

d. cl. dermatic (trophospongial) cliusters.

e. c. embryonic coeloma.

ep. epiblast.

ex.c. exocoeloma.

f. b.v. foetal bloodvessels and capillaries.

f. ep. formative epiblast.

f.g. foregut.

f. pl. p. false placental pad.

h. heartrudiment.

hy. hypoblast.

m. a. maternel arteries.

m. a. b.l. maternel arterial bloodlacunes.

m. b.l. maternel bloodlacunes.

med. medullary tube.

mes.c. mesencephalon.

mes. gr. mesometrical groove.

mes.m. mesometrium. a. c. amnion cavity.

m. u. muscularis uteri.

muc. mucosa uteri.

o. v. optic vesicle.

per. pericard.

pl. p. placental pad.

p. pi. placental pit.

pl.tr. plasmoditrophoblast.

pr.a. proamnion.

pr. str. primitive streak.

rh. rhombencephalon.

s. amn. somatic amnion.

s. c. syncytial clusters.

s. m. somatic mesoderm.

som. somites.

s. t. syncytial tissue of the placental pad.

T. trunkregion.

Ta: tailregion.

tr. trophoblast.

tr.d. trophoderm (ectoplacenta)

tr.d. b.l. trophodermal bloodlacunes.

tr.sp. trophospongia.

tr.sp. bl. trophospongial bloodlacunes.

tr. st. transitional stages between uterine capillaries and syncytial clusters.

u. e. uterine epithelium.

u. g. glands.

umb. vesicle.

v. m. ventral mesoblast.

v. o.m. venae omphalomesentericae.

PLATE IV-V.

$\mathrm{N}^{\circ} .2 a$. of the catalogue.

Fig. 1. Section through the vaginal part of the uterine swelling. The germinal vesicle has not yet appeared. Uterine epithelium (u. e.) and uterine glands (u. g.) hatched, connective tissue of the mucosa of the uteri dotted, bloodvessels and capillaries presented by a black tone. $\times 50(2 / 3)$.

Fig. 1a. A part of the preceding section under high power $\times 180(2 / 3)$.

Fig. 2. Section through the gestation-sack in the region of the embryonic area. The latter has been cut in obliquely sagittal direction. Formative epiblast, trophoblast, bloodvessels and syncytial clusters presented by a black tone, germinal mesoblast, outer muscular layer and connective tissue of the uterine mucosa dotted, uterine epithelium and glands hatched, hypoblast presented by a continuous line with black dots. $\times 35(2 / 3)$.

Fig. 3. Section through the gestation-sack to the left side of the embryonic area. A spacious exoecoeloma is present. Its outer wall has not get united with the true placental pad. Mesoblast presented by :a dotted line. $\times 35(2 / 3)$.

Fig. 4. Section through the embryonic margin of the placenta. The placental cushion projects into the exocoeloma. Trophospongia dotted, syncytial clusters double hatched, cytotrophoblast distinguished from plasmoditrophoblast by the presence of schematic cell-limits, mesoblastic covering of the cushion presented by a continuous line with black dots. $\times 100(2 / 3)$.

Fig. 5. Section through the mid-placental region of the gestationsack. The inverse trophodermal cone with deep central pit single hatched, the syncytial clusters distinguished from the further trophospongia by a much denser dotting. $\times 35\left({ }^{2} / 3\right)$. 
Fig. 6. Section through the central region of the placenta, showing the spacious trophodermal bloodlacumar system surrounded by plasmoditrophoblast, the penetration of the trophodermal cone into the subjacent placental pad and the histological differentiation of the latter. Cytotrophoblast coarsely dotted, plasmoditrophoblast finely dotted, unchanged trophospongia single hatched, syncytial clusters double hatched, derimatic or trophospongial clusters hatched and dotted. $\times 50\left({ }^{2} / 3\right)$.

Fig. 7. Section through the posterior (antembryonic) part of the placenta, showing the original connection of the yolk-hypoblast with the placental cushion. Trophospongial or dermatic clusters presented by a dense dotting. $\times 50(2 / 3)$.

Fig. 8. Section through the true placental pad, showing the size of syncytial clusters. $\times 180(2 / 3)$.

Fig. 9. Section through the false placental pad, showing the transition of maternal capillaries into syncytial clusters. $\times 180\left({ }^{2} /{ }_{3}\right)$.

Fig. $10 \& 11$. Details from the same region drawn under high power. $\times 360(1 / 2)$.

$N^{\circ} .1 a$ of the catalogue.

Fig. 12 and 13. Two sections through the border of the placental pad and the muscularis uteri showing the communication and transition of maternal veins into the spaces of the syncytial clusters. The protoplasma of the clusters dotted. $\times 180(2 / 3)$.

\section{PLATE VI-VII.}

No. $1 a$ of the catalogue.

Fig. 14. Central section through the gestationsack in the embryonic and placental region. The embryo is cut in nearly sagittal direction. The yolksack and the wide opened enteron lie at the right side of the drawing, the placenta, the exocoeloma and the back of the embryo are at the left side of it. Allantois and proamnion are present. The amnion-cavity and the neural tube are closed. The placental cushion projects far into the exocoeloma. $\times 35(1 / 3)$.

Fig. 15. Section through the central part of the placenta. Mind the proximity of the placental surface and the area vasculosa. Trophoderma dotted, trophospongia single hatched, syncytial clusters double hatched. $\times 40(2 / 3)$.

Fig. 16 and 17. Two sections through the central region of the placenta, showing the direct communication of the maternal arteries with the trophodermal bloodlacunes. The black spots are clusters of highly coloured trophospongial cells. Cytotrophoblast densely, plasmoditrophoblast widely dotted. $\times 100(3 / 4)$.

\section{$\mathrm{N}^{\circ} .9$ of the catalogue.}

Fig. 18. Section through the gestationsack on the level of the headregion of the embryo and of the embryonic margin of the placental cushion, showing a rudiment of the proamnion, the closed brain tube, the separated foregut, the pericard with heartrudiment, the placental cushion with large central pit and the spongious placental pad. $\times 35(2 / 3)$.

Fig. 19. Section through the midplacental region showing the narrow exocoeloma, the deep central pit bridged by a mesoblastic membrane and the nearly total syncytial degeneration of the spongious tissue of the placental pad. In the central part of the trophoderma a maternal artery is visible, in the muscularis a maternal vein communicates with a trophospongial lacune. $\times 50(2 / 3)$.

Fig. 20. Section through the primitive streak and the closed tailamnion of the embryonic region and through the embryonic margin of the placenta. $\times 100(2 / 3)$.

Fig. 21. Section through the central pit, showing the ingrowth of cytotrophoblastic villi and the coating of the trophodermic bloodspaces with plasmoditrophoblast, these two layers of the trophoderma being separated by narrow spaces. Observe the maternal artery in the basal part of the drawing. $\times 180(2 / 3)$.

\section{$\mathrm{N}^{\circ} .10$ of the catalogue.}

Fig. 22. Section through the gestationsack in the embryonic and placental region. The foetal membranes have been damaged in such a manner that the course of these structures cannot be determined exactly. The rolling up of the embryo is cause that it is cut thrice, once through the headregion, a second time through the posterior truncregion and a third time through the tailregion. Mind the communication of the exocoeloma with the embryonic coeloma. Through the pits and the cytotroblastic villi the bloodcapillaries of the exocoelomic mesoblast are penetrating into the trophoderma, forming a reticulum intermingling with that of the trophodermal (maternal) bloodlacunes. In the central region there is a wide communication of the latter with an enormous arterial(?) bloodspace in the placental pad. Rest of the communication of the yolksack with the enteron proper. $\times 35(2 / 3)$.

Fig 23. Section through the right half of the central placental region showing the same features as Fig. .22 under somewhat higher power. $\times 60(2 / 3)$.

Fig. 24. Tangential section through the margin of the placental cushion, showing the intermingling of foetal capillaries and maternal bloodspaces, the latter lined by plasmoditrophoblastic pseudendothelium. $\times 180(2 / 3)$. 

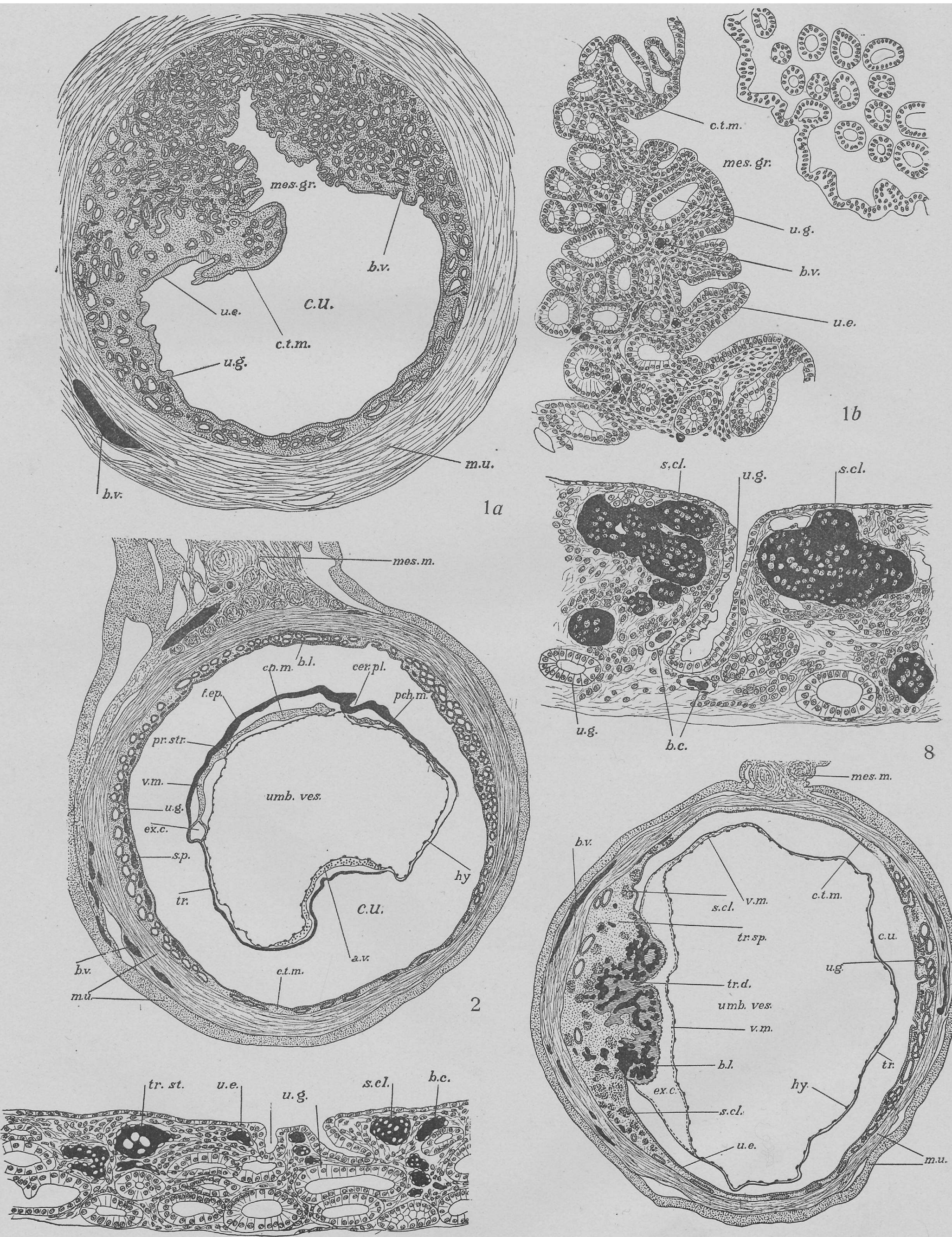


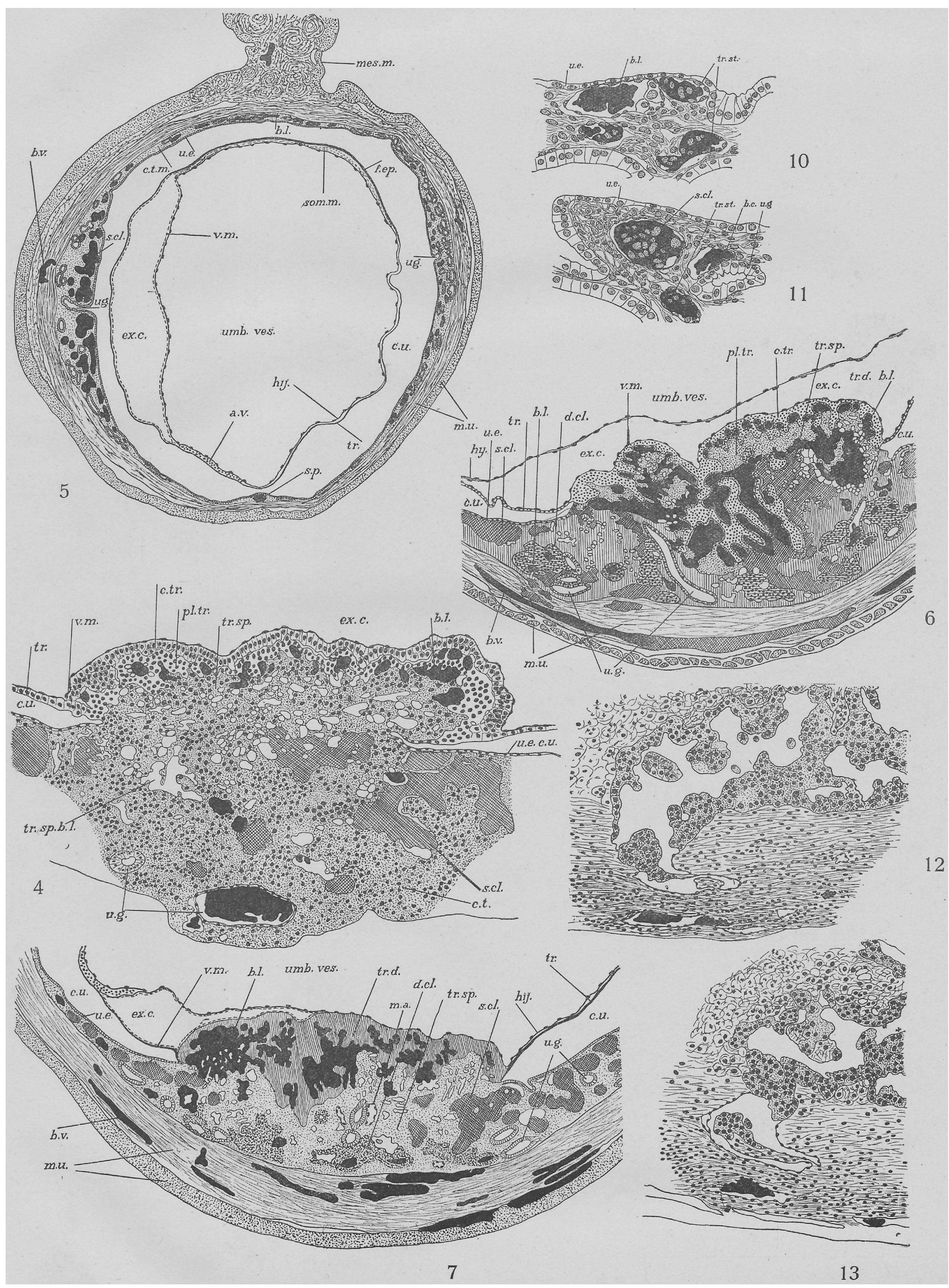




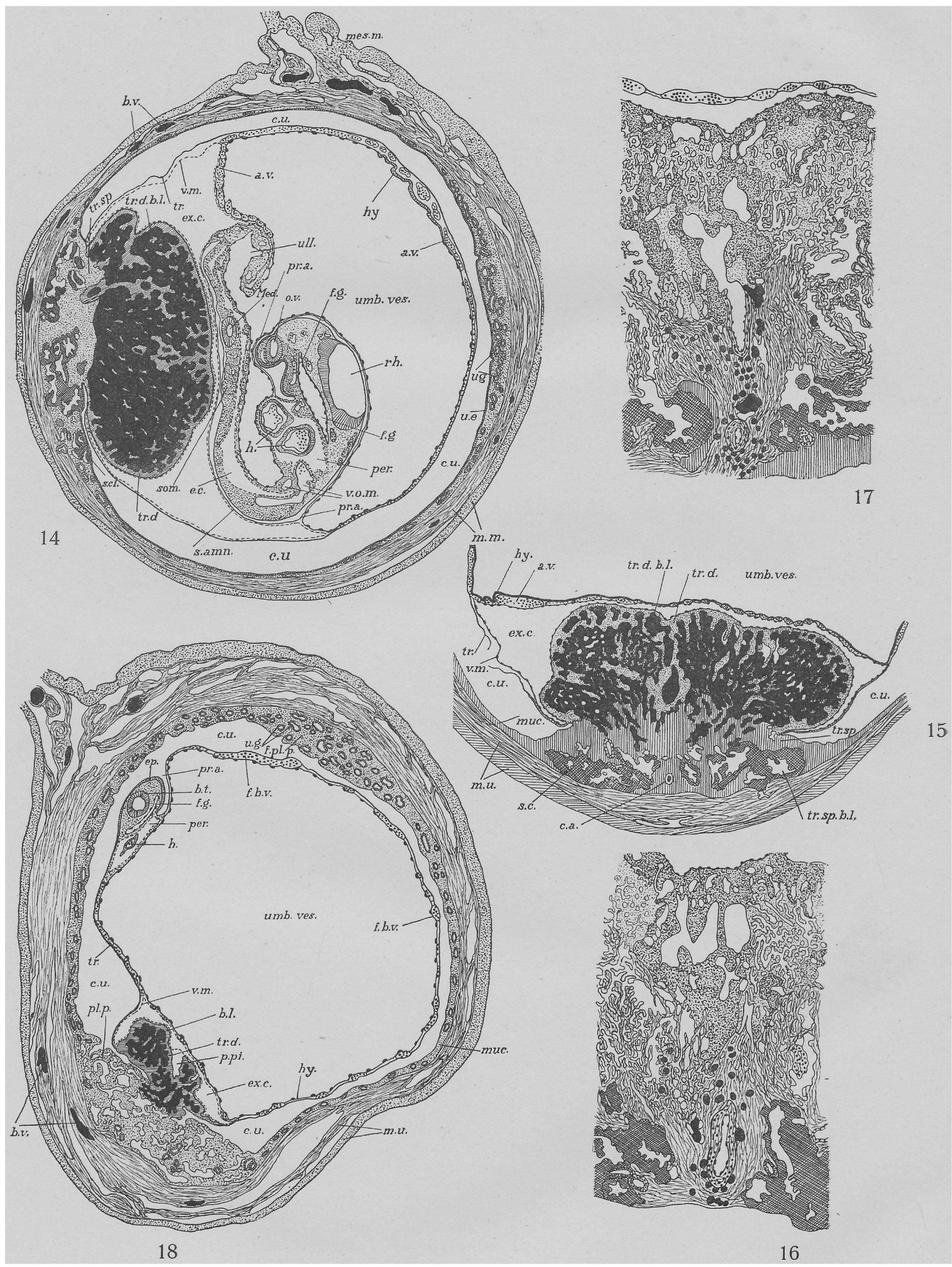




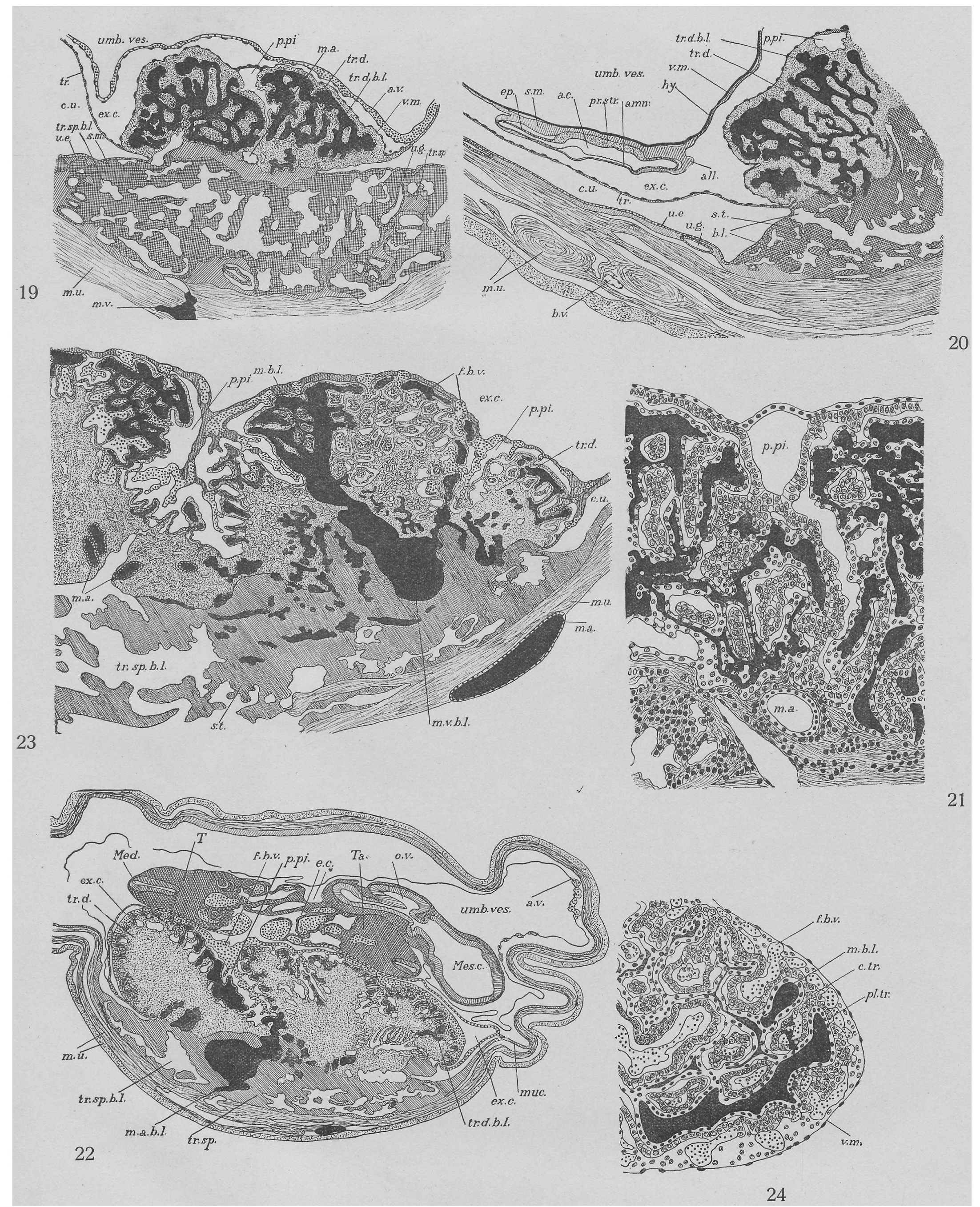

